American Medical Journal 2 (2): 93-97, 2011

ISSN 1949-0070

(C) 2011 Science Publications

\title{
Does Childhood Asthma Increase the Risk of Mood Disorders in Later Life?
}

\author{
${ }^{1}$ Wenbin Liang and ${ }^{1,2}$ Andy H. Lee \\ ${ }^{1}$ National Drug Research Institute, \\ ${ }^{2}$ School of Public Health, \\ Faculty of Health Science, Curtin University, Perth, WA, Australia
}

\begin{abstract}
Problem statement: As a chronic condition, asthma may increase the risk of mood disorders. Understanding the association between asthma and mood disorders has important implications for asthma treatment and follow-up in primary care settings. Approach: To investigate whether asthma exposure during childhood is associated with the risk of mood disorders during adolescence and young adulthood, a population-based birth-cohort study of males born between 1980 and 1984 in Western Australia was conducted. Participants were identified using birth registry records and observed from age 12 years to December 31st, 2009 or death, whichever occurred first. KaplanMeier survival and Poisson regression analyses were performed to assess the effect of asthma exposure during childhood on the risk of mood disorders. Results: Hospitalization for asthma during childhood was found to be associated with an increased risk of mood disorders. Compared to participants without asthma admission before the age of 12, the relative risk of mood disorders was 1.32 (95\% confidence interval 1.01-1.72) for those hospitalized once to twice for asthma and 1.66 (95\% confidence interval 1.15-2.41) for those hospitalized three or more times for asthma, after controlling for potential confounding variables. Conclusion: The results supported the literature that asthma during childhood could increase the risk of mood disorders in later life. Prevention strategy should be developed to reduce the stress level among children with asthma to protect their normal mental development.
\end{abstract}

Key words: Affective disorder, birth cohort, hospitalization, glucocorticoid level

\section{INTRODUCTION}

Asthma affects children and adults in both industrialised and developing countries (Eder et al., 2006; Russell, 2006; Ahmadi et al., 2009). Despite the current treatment focussing on control of physiological responses to allergens and environmental factors, asthma was once considered a psychological illness, because symptoms of mental disorders were frequently observed among asthmatic patients (Russell, 2006; Chun et al., 2008). The positive association between asthma and mental disorders has been increasingly reported in cross-sectional studies (Chun et al., 2008; Goldney et al., 2003; Goodwin et al., 2005; 2007; Lavoie et al., 2005; Scott et al., 2007; Katon et al., 2007; Daryanavard et al., 2011). However, these crosssectional studies typically could not determine the direction of causality (Scott et al., 2007). Only a few prospective studies have attempted to resolve the issue, two of which reported that asthma led to a higher risk of panic disorders (Goodwin et al., 2003; Hasler et al.,
2005). Corticosteroids, commonly prescribed to treat asthma, may increase the risk of affective disorders in a dose-response manner (Brown et al., 1999; Sirois, 2003). As a chronic condition, recurring symptoms of asthma may also elevate the prevalence of mood (affective) disorders (Lavoie et al., 2005).

Understanding the association between asthma and mood disorders has important implications for asthma treatment and follow-up in the primary care setting. The present study aims to investigate whether asthma exposure during childhood is related to an increased risk of mood disorders during adolescence and young adulthood, using population data from birth cohorts in Western Australia (WA).

\section{MATERIALS AND METHODS}

Databases and variables: Male participants born between 1980 and 1984 were identified by birth registry records and observed from age 12 years to December 31st, 2009 or death, whichever occurred first. Thus,

Corresponding Author: Wenbin Liang, National Drug Research Institute Curtin University GPO Box U 1987,

Perth, WA, 6845, Australia Tel: +61 892661617 Fax: +61 892661611 
consecutive years of follow-up ranged from 13-17 years. Age at 12 years was chosen as the starting point of adolescence following the convention in the literature (Hales et al., 2008). Ethical approval of the study was obtained from the Human Research Ethics Committee of the Department of Health WA.

Information on demographic characteristics (year of birth, age of parents, residential location), hospitalisations for asthma and mental health conditions of the cohort, were obtained from a range of sources and the records were linked by the WA Data Linkage System. Data sources included: (i) Midwives Notifications Data, (ii) mental health service records from the WA Mental Health Ambulatory Data System; (iii) WA Hospital Morbidity Data System; (iv) Birth Registry data; and (v) Mortality Database. Participants who died before the end of follow-up (December 31th 2009) were identified from the WA Mortality Database. The Midwives Notifications Data covered all births attended by a registered midwife (more than $99 \%$ of all births), while the WA Hospital Morbidity Data System included separations from all public and private hospitals in the State. The reliability and quality of these linked data have been confirmed (Holman et al., 1999). The mental health service records included all public and private psychiatric hospitals and captured all attendances at public psychiatric outpatient clinics.

ICD-9 codes (493.0, 493.1, 493.8 and 493.9) and ICD-10 codes (J45 and J46) were used within the study period to identify asthma admissions. Outpatient services and hospital admissions for mood disorders were identified by diagnostic codes 296.x (ICD-9) and F30-F39 (ICD-10), which included manic episode, depressive disorders and bipolar disorders. For those participants with multiple episodes, their records were sorted by age.

To ascertain socio-economic status, residential location at birth was recorded with the Australian Bureau of Statistics' Index of Relative Socio-Economic Disadvantage (IRSED), a general measure of economic disadvantage of residential families in an area (McLennan, 1998). Participants who did not have a residential address in WA at birth were subsequently excluded, since their morbidities were unlikely to be captured by the WA Data Linkage System. Participants with missing demographic information or died at or before the age of 12 were also removed.

Statistical analysis: The cumulative risks of mood disorders in relation to the frequency of asthma admission before 12 years of age were compared using the Kaplan-Meier survival curve. Poisson regression analysis was then undertaken to determine the effect of asthma exposure during childhood on the risk of mood disorders, accounting for potential confounding variables, namely, age of parents at delivery, birth weight, Apgar score at five minutes, IRSED, the presence of mood disorder before age 12 and asthma hospitalisation after age 12 .

\section{RESULTS}

Of the total 49, 210 participants available for analysis, 922 were diagnosed with mood disorders sometime during the follow-up period. As shown in Fig. 1, the risk of mood disorders during the follow-up was higher among those who had been hospitalised for asthma before the age of 12 years and particularly for males sustaining three or more asthma admissions; the dose-response relationship being significant according to the log-rank test $(\mathrm{p}=0.001)$.

Table 1 presents the results of Poisson regression analysis. It is evident that the association between childhood asthma hospitalisation and risk of mood disorders in later life remained significant after controlling for the effects of confounding variables.

Table 1:Association between asthma exposure and risk of mood disorders

\begin{tabular}{|c|c|c|c|c|}
\hline & $\begin{array}{l}\text { Number of first } \\
\text { diagnosed mood }\end{array}$ & $\begin{array}{l}\text { Persons at risk } \\
\text { disorders }\end{array}$ & $\begin{array}{l}\text { Incidence } \\
\text { rate ratio }\end{array}$ & $\begin{array}{l}95 \% \text { confidence } \\
\text { interval }\end{array}$ \\
\hline \multicolumn{5}{|c|}{$\begin{array}{l}\text { Asthma admission } \\
\text { before age } 12\end{array}$} \\
\hline No & 830 & 45,829 & 1.00 & \\
\hline 1 to 2 times & 59 & 2,393 & 1.32 & $(1.01,1.72)$ \\
\hline 3 or more times & 33 & 988 & 1.66 & $(1.15,2.41)$ \\
\hline \multicolumn{5}{|c|}{$\begin{array}{l}\text { Asthma admission } \\
\text { after age } 12\end{array}$} \\
\hline No & 900 & 48,558 & 1.00 & \\
\hline 1 or more times & 22 & 652 & 1.38 & $(0.87,2.17)$ \\
\hline \multicolumn{5}{|l|}{$\begin{array}{l}\text { Mood disorder } \\
\text { before age } 12\end{array}$} \\
\hline No & 850 & 47,545 & 1.00 & \\
\hline Yes & 72 & 1,665 & 2.41 & $(1.89,3.07)$ \\
\hline \multicolumn{5}{|c|}{ Agpar score at $5 \mathrm{~min}$} \\
\hline$<7$ & 25 & 1,041 & 1.00 & \\
\hline$\geq 7$ & 897 & 48,169 & 0.79 & $(0.53,1.17)$ \\
\hline \multicolumn{5}{|l|}{ Birth weight } \\
\hline$<2500 \mathrm{~g}$ & 39 & 2,194 & 1.00 & \\
\hline$\geq 2500 \mathrm{~g}$ & 883 & 47,016 & 1.11 & $(0.80,1.53)$ \\
\hline \multicolumn{5}{|l|}{ Age of mother } \\
\hline $12-17 \mathrm{yrs}$ & 22 & 704 & 1.43 & $(0.92,2.24)$ \\
\hline $18-24$ yrs & 334 & 16,366 & 1.00 & \\
\hline $25-29 \mathrm{yrs}$ & 334 & 19,438 & 0.89 & $(0.75,1.06)$ \\
\hline $30-34$ yrs & 173 & 9,986 & 0.83 & $(0.65,1.04)$ \\
\hline $35-39$ yrs & 52 & 2,407 & 0.89 & $(0.63,1.27)$ \\
\hline$\geq 40 \mathrm{yrs}$ & 7 & 309 & 0.87 & $(0.39,1.91)$ \\
\hline \multicolumn{5}{|l|}{ Age of Father } \\
\hline $12-17 \mathrm{yrs}$ & 2 & 103 & 0.69 & $(0.17,2.85)$ \\
\hline $18-24 \mathrm{yrs}$ & 191 & 8,463 & 1.00 & \\
\hline $25-29 \mathrm{yrs}$ & 309 & 18,116 & 0.85 & $(0.69,1.04)$ \\
\hline $30-34$ yrs & 242 & 14,596 & 0.88 & $(0.70,1.12)$ \\
\hline $35-39 \mathrm{yrs}$ & 123 & 5,668 & 1.18 & $(0.89,1.57)$ \\
\hline$\geq 40 \mathrm{yrs}$ & 55 & 2,264 & 1.30 & $(0.90,1.86)$ \\
\hline \multicolumn{5}{|c|}{$\begin{array}{l}\text { Index of relative socio- } \\
\text { economic disadvantage }\end{array}$} \\
\hline 1st quintile & 204 & 9,763 & 1.00 & \\
\hline 2nd quintile & 175 & 9,429 & 0.89 & $(0.73,1.09)$ \\
\hline 3rd quintile & 216 & 10,990 & 0.94 & $(0.77,1.14)$ \\
\hline 4th quintile & 195 & 11,568 & 0.82 & $(0.68,1.00)$ \\
\hline 5th quintile & 132 & 7,460 & 0.86 & $(0.68,1.07)$ \\
\hline
\end{tabular}




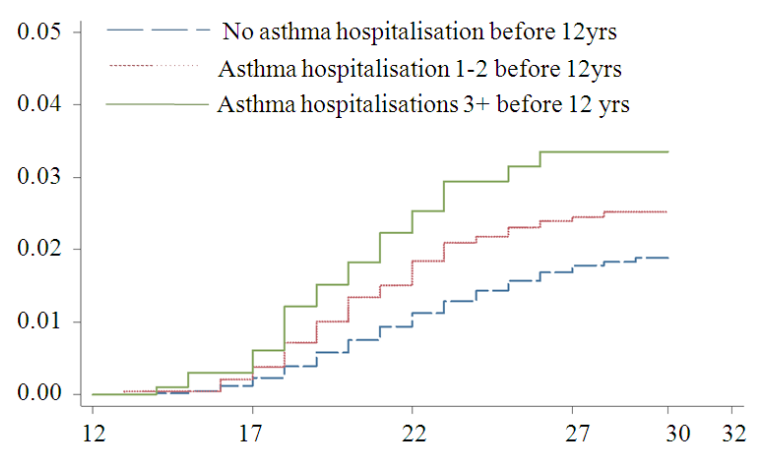

Fig. 1: Cumulative risk of mood disorders by number of asthma hospitalisations before 12 years of age

Moreover, participants who were admitted for asthma after the age of 12 years appeared to incur an elevated risk of mood disorder, though the increase in risk did not attain statistical significance and only 22 cases were reported at this exposure category.

\section{DISCUSSION}

In this birth-cohort study, hospitalisation for asthma during childhood was found to be associated with an increased risk of mood disorders in later life. The results were consistent with findings from previous cross-sectional studies which showed high prevalence of co-existing asthma and certain mental disorders (Chun et al., 2008; Goldney et al., 2003; Goodwin et al., 2005; 2007; Lavoie et al., 2005; Scott et al., 2007; Katon et al., 2007).

The underlying causes for the observed associations are not entirely clear, but likely to be related to the chronic stress from asthma and the corticosteroid therapy in treating asthma. Firstly, similar to other chronic conditions, persisting asthma status can result in chronic stress, whereas acute asthma exacerbation can lead to a high level of acute stress (Scott et al., 2007; Cohen and Rodriquez, 1995). Both chronic stress and repeated acute stress increase the activity of hypothalamic-pituitary-adrenal HPA axis (Juster et al., 2011), which in turn increase the glucocorticoid level. Such a rise in glucocorticoid alters neuronal activities and gene expression, especially in the limbic system which is an important area for memory and emotion and is closely linked to mood and anxiety disorders. Evidence from both animal and human studies have suggested that an increase in glucocorticoid level can affect brain function and development, such as impairment of long-term potentiation, structural plasticity changes in the hippocampus and amygdala, impairments in cognitive function and changes in behaviours (McEwen, 2005; Sousa et al., 2008). Secondly, corticosteroid therapy is widely used for treating moderate and serious forms of asthma exacerbation (Peter et al., 2002). This therapy directly increases exogenous glucocorticoid level in plasma and tissues. Exogenous glucocorticoid is known to have adverse effects on central nervous system, including mood disturbance and increase the risk of mood disorders and other psychiatric disorders (Warrington and Bostwick, 2006). During childhood, high exogenous glucocorticoid level (by therapy) and/or endogenous glucocorticoid level (by asthma-induced stress) may alter limbic system structure or interrupt its normal development as well as other parts of the brain (Lupien et al., 2009), consequently increases the risk of mood disorders in later life.

Unlike cross-sectional retrospective studies in the literature, the present study investigated the association between childhood asthma exposure and mood disorders in a prospective manner, using populationbased birth cohorts with large sample sizes and a relatively long period of follow-up. Therefore, our findings were not affected by recall bias. The main limitation was the lack of female participants. However, in view of the role of oestrogen in the onset of mood disorder (Halbreich and Kahn, 2001), this study focused on males only. Moreover, there were insufficient cases to estimate the risks of different subtypes of mood disorders, among those who experienced serious asthma exacerbation or with a history of chronic asthma. A study adopting a casecohort design is recommended to test the hypothesis.

\section{CONCLUSION}

In conclusion, this population-based male birthcohort study found that serious asthma condition during childhood was associated with an increased risk of mood disorders in later life. Prevention strategy should be developed to reduce the stress level among children with asthma to protect their normal mental development.

\section{ACKNOWLEDGMENT}

The researchers declare that there are no financial and other conflicts of interest.

\section{REFERENCES}

Ahmadi, E., Z. Rahnama and A.R. Tehrani, 2009. Atopic dermatitis and type 1 diabetes mellitus in iranian children. Am. J. Immunol., 5: 98-100. DOI: 10.3844/ajisp.2009.98.100 
Brown, E.S., D.A. Khan and V.A. Nejtek, 1999. The psychiatric side effects of corticosteroids. Annals Allergy, Asthma Immunol., 83: 495-504. DOI: 10.1016/S1081-1206(10)62858-X

Chun, T.H., S.H. Weitzen and G.K. Fritz, 2008. The asthma/mental health nexus in a population-based sample of the united states. Chest, 134: 1176-1182. DOI: 10.1378/chest.08-1528 PMID: 18719055

Cohen, S. and M.S. Rodriquez, 1995. Pathways linking affective disturbances and physical disorders. Health Psychol., 14: 374-380. DOI: 10.1037/02786133.14.5.374 PMID: 7498107

Daryanavard, A., A. Madani, M.S. Mahmoodi, S. Rahimi and F. Nourooziyan et al., 2011. Prevalence of depression among high school students and its relation to family structure. Am. J. Applied Sci., 8: 39-44. DOI: 10.3844/ajassp.2011.39.44

Eder, W., M.J. Ege and E. Von Mutius, 2006. Current concepts: The asthma epidemic. N. Eng. J. Med., 355: 2226-2235. DOI: 10.1056/NEJMra054308 PMID: 17124020

Goldney, R.D., R. Ruffin, L.J. Fisher and D.H. Wilson, 2003. Asthma symptoms associated with depression and lower quality of life: A population survey. Med. J. Aust., 178: 437-441. PMID: 12720509

Goodwin, R.D., C. Faravelli, S. Rosi, F. Cosci and E. Truglia et al., 2005. The epidemiology of panic disorder and agoraphobia in Europe. Eur. Neuropsychopharmacol., 15: 435-443. DOI: 10.1016/j.euroneuro.2005.04.006 PMID: 15925492

Goodwin, R.D., F. Jacobi and W. Thefeld, 2003. Mental disorders and asthma in the community. Arch. Gen. Psychiatry, 60: 1125-1130. DOI: 10.1001/archpsyc.60.11.1125 PMID: 14609888

Goodwin, R.D., S. Chuang, N. Simuro, M. Davies and D.S. Pine, 2007. Association between lung function and mental health problems among adults in the United States: Findings from the first national health and nutrition examination survey. Am. J. Epidemiol., 165: 383-388. DOI: 10.1093/aje/kwk026 PMID: 17158187

Halbreich, U. and L.S. Kahn, 2001. Role of estrogen in the aetiology and treatment of mood disorders. CNS Drugs, 15: 797-817. DOI: 10.2165/00023210200115100-00005 PMID: 11602005

Hales, R.E., S.C. Yudofsky and G.O. Gabbard, 2008. American Psychiatric Publishing Textbook of Psychiatry: Textbook of Psychiatry. 5th Edn., American Psychiatric Publishing, ISBN-10: 1585622575, pp: 1786.
Hasler, G., P.J. Gergen, D.G. Kleinbaum, V. Ajdacic and A. Gamma et al., 2005. Asthma and panic in young adults: A 20-year prospective community study. Am. J. Respir. Crit. Care Med., 171: 12241230. DOI: $10.1164 / \mathrm{rccm} .200412-16690 \mathrm{OC}$ PMID: 15764721

Holman, C.D., A.J. Bass, I.L. Rouse and M.S. Hobbs, 1999. Population-based linkage of health records in Western Australia: Development of a health services research linked database. Aus. N. Z. J. Public Health, 23: 453-459. PMID: 10575763

Juster, R.P., G. Bizik, M. Picard, G. Arsenault-Lapierre and S. Sindi et al., 2011. A transdisciplinary perspective of chronic stress in relation to psychopathology throughout life span development. Dev. Psychopathol., 23: 725-726. DOI: $\quad 10.1017 /$ S0954579411000289 PMID: 21756430

Katon, W., P. Lozano, J. Russo, E. McCauley and L. Richardson et al., 2007. The Prevalence of DSMIV Anxiety and depressive disorders in youth with asthma compared with controls. J. Adolescent Health, 41: 455-463. DOI: 10.1016/j.jadohealth.2007.05.023 PMID: 17950165

Lavoie, K.L., A. Cartier, M. Labrecque, S.L. Bacon and C. Lemiere et al., 2005. Are psychiatric disorders associated with worse asthma control and quality of life in asthma patients? Respiratory Med., 99: 1249-1257. DOI: 10.1016/j.rmed.2005.03.003 PMID: 16140225

Lupien, S.J., B.S. McEwen, M.R. Gunnar and C. Heim, 2009. Effects of stress throughout the lifespan on the brain, behaviour and cognition. Nat. Rev. Neurosci., 10: 434-445. DOI: 10.1038/nrn2639 PMID: 19401723

McEwen, B.S., 2005. Glucocorticoids, depression and mood disorders: Structural remodeling in the brain. Metab. Clin. Exp., 54: 20-23. DOI: 10.1016/j.metabol.2005.01.008 PMID: 15877308

McLennan, W., 1998. 1996 census of population and housing: selected family and labour force characteristics, Australia. 1st Edn., Australian Bureau of Statistics, Canberra, pp: 106.

Peter, P.V.A., C.M. Mellis and P.D. Sly, 2002. The role of corticosteroids in the management of childhood asthma. Med. J. Aus., 176: 168-173. PMID: 11913918

Russell, G., 2006. The childhood asthma epidemic. Thorax, 61: 276-277. DOI: 10.1136/thx.2005.052662 PMID: 16565264 
Scott, K.M., M.V. Korff, J. Ormel, M.Y. Zhang and R. Bruffaerts et al., 2007. Mental disorders among adults with asthma: Results from the world mental health survey. General Hospital Psychiatry, 29: 123-133.

10.1016/j.genhosppsych.2006.12.006

DOI: 17336661

Sirois, F., 2003. Steroid psychosis: A review. General Hospital Psychiatry, 25: 27-33. DOI: 10.1016/S0163-8343(02)00241-4
Sousa, N., J.J. Cerqueira and O.F.X. Almeida, 2008. Corticosteroid receptors and neuroplasticity. Brain Res. Rev., 57: 561-570. DOI: 10.1016/j.brainresrev.2007.06.007 PMID: 17692926

Warrington, T.P. and J.M. Bostwick, 2006. Psychiatric adverse effects of corticosteroids. Mayo Clin. Proc., 81: 1361-1367. DOI: 10.4065/81.10.1361 PMID: 17036562 